\title{
Evaluation of mutant rice genotypes for tolerance to high temperature
}

\author{
María Caridad González Cepero ${ }^{1}$, Elizabeth Cristo ${ }^{1}$, Noraida Pérez ${ }^{1}$, Yanelis Reyes ${ }^{1}$, Dayné \\ Horta $^{1}$, Rodolfo Guillama ${ }^{1}$, Guillermo Blanco ${ }^{1}$, Mario Varela $^{1}$, Madeleine Spencer ${ }^{2}$ and Fatma \\ Sarsu $^{2}$
}

\author{
${ }^{1}$ National Institute of Agricultural Science, Cuba \\ ${ }^{2}$ Joint FAO/IAEA Division of NAFA, Plant Breeding and Genetics Section, IAEA, Vienna, \\ Austria
}

\section{*Corresponding author: mcaridad09@yahoo.es}

\begin{abstract}
Rice (Oryza sativa L.) is planted in about a tenth of the arable area around the world and is the largest source of food energy for half of humanity. Climatic change with increasing frequency of severe and prolonged drought periods and significant increases in air temperature has affected global rice production. Therefore, generating mutant rice cultivars tolerant to high temperatures and low water supplies is of utmost importance. Advanced mutant rice lines which were derived from irradiated Amistad -82 and J-104 were evaluated in the field under high temperatures and low water supply conditions using Amistad-82 variety as control. The genotypes with the best and worst field performances were compared using physiological parameters such as cell membrane thermostability, pollen viability, lipid peroxidation, and peroxidase and catalase activity under high temperature conditions. Three mutant lines, 8852, 8552 and LP-12 showed high yielding under high temperatures and low water supplies conditions in the field and also showed better pollen viability, cell membrane thermo stability, lipid peroxidation and peroxidase than LP-16 mutant lines and the control cv. Amistad-82. These results show that the physical irradiation of seeds with protons followed by subsequent in vitro embryo culture using 2,4D may generate genetic variability for tolerance to high temperatures. The variation observed for the physiological and biochemical indicators evaluated could be used for the early selection of high temperature tolerant rice genotypes.
\end{abstract}

Key Words: Heat stress, rice, mutation, biochemical indicators, proton beam, selection, pollen viability.

Abbreviation: A-82, Amistad-82, FAO - Food and Agricultural Organization, CAT- catalase, CMCT-cell membrane thermo-stability, 2 4D - diclorofenoxiacetic acid, J-104, Jucarito-104, MDA - manoldialdehide, POX-peroxidase, Kin - Kinetine.

Introduction

Rice (Oryza sativa L.) is one of the most important crops produced worldwide and is the staple food for more than a half of the world's population (Yang and Zhang, 2006). With respect to yield, rice is the second most produced crop after maize (Zea mays $\mathrm{L}$.) and is the second highest crop after wheat with respect to the harvested area. Rice provides more calories than other cereals (Acevedo et al., 2006). Therefore, rice is widely grown in many over-populated countries including China, India, Pakistan, Indonesia, Philippines and Japan, where it accounts for about $92 \%$ of the world's total rice production (Kondamudi et al., 2012).

Rice is a main crop in Cuba where annual consumption is about $70 \mathrm{~kg}$ per person, which is well above that of other countries of the American continent. However, rice yields in Cuba are low, around $3 \mathrm{t} / \mathrm{ha}$ and do not meet the national demand (Morejón et al., 2012). Studies revealed that low rice yields in Cuba are associated with different types of abiotic and biotic stresses. Heat has been identified as the most important environmental stress limiting yield. Heat stress alters molecular and physiological processes affecting crop growth and yield (Mittler et al., 2012; Hasanuzzaman et al., 2013). Plants can modify their metabolism in various ways in response to heat stress, notably by generating compatible solutes that are able to help maintain proteins and cellular structures, maintain cell turgor pressure, and modify antioxidant mechanisms to re-establish cellular redox homeostasis (Munns and Tester, 2008; Janska et al., 2010). Key physiological and biochemical indicators of heat stress tolerance include electrolyte leakage and lipid peroxidation levels i.e. Malondialdehyde (MDA) content and anti-oxidant enzyme activity (Campos et al., 2003;
Heath et al., 1986; Bajji et al., 2001; Nakano and Asada, 1981; Oberley and Spitz, 1985).

Mutation induction can contribute to plant improvement when combined with efficient screening methods. Plant mutation breeding has been very successful in rice and has produced around 850 mutant rice cultivars (FAO /IAEA Mutant variety database, 2017). Mutation breeding in rice has not only been successful in higher yielding cultivar production, notably the semi-dwarfs, but has also produced mutants for biotic and abiotic stress tolerance. Gamma irradiation in mutation breeding is an effective technique in creating new variation for the rapid breeding of new cultivars (Tembo and Munyinda, 2015). In Cuba, irradiation with protons has been used to generate genetic variability and a new rice cultivar with good productive potential and salinity tolerance has been developed at the National Institute of Agricultural Sciences (INCA) (González et al., 2009). The objective of the current study was to evaluate mutant lines generated by proton beam and in vitro culture to select for high temperature tolerance, which may better adapt to climate change stressors.

\section{Results}

Evaluation of advanced mutant lines under high temperature condition in the field

The mutant lines and cv. A-82 showed difference as compared to the LP-16 mutant line in all evaluated characters. All mutants except for LP-16 out-performed the control cv. A-82 in yield, number of panicles per plant and number of full grains per panicle. The mutants, 8552, 8553 and LP-12 out-performed 
the rest of the mutant lines as well as the A-82 Cuban cultivar (parent) in the number of panicles per $\mathrm{m}^{2}$, the number of full grains per panicle, the weight of 1,000 grains and the yield under high temperature and low water supply conditions. A poor performing genotype under field conditions was from the mutant line LP-16 which recorded several negative traits for yield and yield components. This mutant has good agronomical performance in the winter season, but it is susceptible to high temperature which has strong negative effects on grain filling. Three of the best-performing mutants under the high temperature condition were8552, 8553 and LP-12, and these were selected for evaluation in farmer's fields with high scale production in multi-locational trials. The mutant LP-16 and A82, which showed poor performance in those conditions, were selected as negative controls for the physiological and biochemical evaluations.

\section{Effect of high temperature on physiological and biochemical parameters}

Two physiological parameters, cell membrane thermostability and pollen viability, were used to characterise the mutants (LP12,8552 , and 8553) for tolerance to high temperatures and compared to LP-16 and cv. A-82.

The susceptible LP-16 showed lower cell membrane thermostability than the other genotypes used for the analysis under heat stress conditions. Highest cell membrane thermostabilities under heat stress, however, were observed for 8553,8552 and LP-12 mutants. These mutant lines also showed remarkably better performance than cv. A-82.

As for the pollen viability (Table 1), significant differences were observed among the genotypes. When the genotypes were exposed to the same heat stress, the effect was very strong on the susceptible LP-16 genotype, as its performance also coincided with the field data at high temperatures. Among the four lines tested, the lowest pollen viability was observed for LP-16 mutant. In contrast, the pollen viability of the LP-12, 8552 and 8553 mutants were two-fold higher than LP-16 line. Moreover, in the high temperature treatment, the pollen viability of LP-12, 8552 and 8553 mutants were only slightly lower than that of the control.

\section{Biochemical evaluation of the selected mutant lines and the susceptible genotypes}

For biochemical evaluation, we analysed catalase activity, peroxidase activity and malondialdehyde content among the selected mutant genotypes. The susceptible LP-16 and cv. A-82 were used as controls during the analyses.

Fig 1. shows the catalase activity difference between two treatments, $25^{\circ} \mathrm{C}$ as control and $40^{\circ} \mathrm{C}$ for 3 hours as a heat stress. Compared to the control temperature, the catalase activity appeared in the mutant LP-12, 8552 and 8553 genotype sat the high temperature treatment of $40^{\circ} \mathrm{C}$. In general, catalase activity among the mutants was significantly higher, and the highest value was observed in the mutant 8553 genotypes (Figure 2). The lowest level was observed in the mutant LP-16 genotype after heat treatment.

A similar pattern was observed among the mutant genotypes for peroxidase activity. These values are also given in figure 2 . Compared to the control treatment, heat stress treatment resulted in higher peroxidase activity in the mutant LP-12, 8552 and 8553 genotypes. The peroxidase activity of these three mutants was higher than the control and the highest value was recorded for the mutant 8553 . The lowest peroxidase activity among the mutants was- measured in the mutant LP-16 genotype, and this value was also significantly lower than that of the control treatment (Figure 3).

Various biochemical differences were observed in terms of the malondialdehyde content among the genotypes evaluated. Considering the high heat stress treatment, while the LP-16 genotype showed an increase in malondialdehyde content, the mutant 8553 genotypes did not show differences between the control and high temperature treatment. The 8552 and LP-12 genotypes, however, showed a slight decrease under stress conditions (Figure 4).

\section{Discussion}

Yield is the end product of plant cultivation and is the result of genotype interactions with the environmental abiotic and biotic factors. Hence, environmental stresses such as heat have become a yield limiting factor in many areas in the world (Wang et al, 2003). The increase in temperature has exposed most crops to heat stress during various stages of their life cycle. It is difficult to predict future climate change effects on agricultural productions (Watanabe and Kume, 2009).

Rice is relatively a tolerant plant to high temperatures during the vegetative stage; however, it is extremely susceptible during the reproductive stage, and particularly during the flowering stage (Jagadish et al., 2010). High or low temperatures during the flowering stage can affect fertilization and seed production of rice, and consequently yield (Das et al., 2014). Rice is mostly grown in those regions where current temperatures are close to optimum for rice production. Therefore, any variation, and particularly increases above optimum production temperatures even for short periods will reduce grain yield.

Recent studies have estimated that rice yields may be reduced by $41 \%$ by the end of the $21^{\text {st }}$ century due to high temperatures (Ceccarelli et al.,2010). For example, reduction in tillering and plant height during the vegetative stage and number of panicles and grain filling during maturation in the reproductive stage may be expected under high temperatures (Yoshida, 2006). Increasing temperatures also hinder translocation of photosynthatse to grains due to elevated respiration rates (Morita, 2003; Zakaria et al., 2004). The optimum temperature range is 27 to $32^{\circ} \mathrm{C}$ (Yin et al.,1996) and the maximum temperatures that can be endured is around $35^{\circ} \mathrm{C}$; thus, the evaluation of genotype performances at $40^{\circ} \mathrm{C}$ in this study is a good bench mark to differentiate the susceptible and tolerant mutant genotypes.

Genetic improvement represents a major tool in developing heat tolerant rice cultivars and mutation induction is of importance in this respect. The IAEA Mutant Variety Database lists 85 drought-tolerant rice mutant cultivars, 31 salinity-tolerant rice genotypes and 11 high-temperature tolerant rice mutant cultivars (FAO/IAEA database, 2017). Most of these mutants have been induced by gamma irradiation, and no rice mutant cultivar has yet been reported from proton treatments, which has been successfully used in Cuba to generate mutants tolerant to salinity and drought (González et al., 2008, González et al., 2016). The present study also verified that the use of protons is adequate to induce tolerance to high temperatures.

\section{Effect of high temperature on physiological and biochemical parameters}

Pollen viability at high temperatures is a crucial factor for better grain set and yield. In riceplants, the flowering stage is highly sensitive to heat stress as drastic temperature fluctuations within the day and even at night affects fertility and seed production, and consequently, causes yield loss (Das et al.,2014; Ziska and Manalao, 1996). However, the selected mutant lines studied here produced pollen with high viability, thus guaranteeing fertilization and seed set under high temperatures. Furthermore, these selected mutants produced a high number of filled grain and better yield than their donor cultivar at high temperature conditions.

In terms of electrolytic conductance, this is correlated with the degree of heat stability of photosynthetic activity in isolated chloroplasts and with the degree of heat tolerance at the whole plant level (Sullivan, 1977). Hence, cell membrane thermostability can be considered as a significant indicator for heat tolerance. In this study, LP-16 showed a remarkably high 
level of damage in cell membrane thermostability relative to other genotypes and this genotype is known to be very susceptible to high temperature in field conditions.

We analysed three biochemical parameters: catalase activity, peroxidase activity and malondialdehyde content. Our study revealed that malondialdehyde content is not a prominent heat stress indicator, as selected mutants showed no significant differences under high temperatures. The malondialdehyde content increased in the susceptible LP-16 and donor A-82 genotype (this is an indicator of oxidative damage caused by the heat stress). However, the performances of the selected mutants LP-12, 8552 and 8553 were not so different relative to the donor A-82 genotype, i.e. there were no significant difference in malondialdehyde content after high stress treatment.

In contrast to the malondialdehyde content, the study revealed that peroxidase activity and catalase activity were significantly affected by heat stress and may be considered as indicators of heat stress (Dolatabadian and Saleh, 2009). Between the two indicators, peroxidase activity was the most distinctive as it showed the most dramatic differences. The reasons may be due to heat effects on cellular homeostasis, e.g. by the formation of reactive oxygen species (ROSs), which damage normal plant metabolism (Shao, 2008; Imlay, 2003). The actions of ROSs lead to non-selective oxidation of proteins and lipids (Joseph and Jini, 2011). To limit oxidative damage, plants have developed a series of detoxification systems, which are composed of enzymatic and non-enzymatic mechanisms. The enzymatic system involved in superoxide dismutase (SOD) eliminates oxygen-free $\left(\mathrm{O}_{2}{ }^{-}\right)$ radicals and molecular oxygen, and finally produces hydrogen peroxide $\left(\mathrm{H}_{2} \mathrm{O}_{2}\right)$.

The $\mathrm{H}_{2} \mathrm{O}_{2}$ is removed by the actions of catalases and peroxidases (Dolatabadian and Saleh, 2009). Several authors suggest that increased peroxidase and other enzyme activities in many plants are involved in the elimination of ROSs and provide protection from oxidative stress (Kartashov et al., 2008). Here the increase in peroxidase activity in the 8552,8553 and LP-12 mutants can be associated with the response of these mutant genotypes to remove the $\mathrm{H}_{2} \mathrm{O}_{2}$ formed as a consequence of high temperature (Figure 1 and 2) (Blokina et al., 2003).

The evaluation of the physiological and biochemical indicators allowed associations to be made with field performance under high temperature stress. The mutants 8552, 8553 and LP-12 showed good agronomic performance under high temperature conditions in the field and this was associated with some specific physiological and biochemical responses (pollen viability, catalase and peroxidase activity) which may explain their tolerance. This study has highlighted associations between specific biochemical mechanisms and field performance in rice subject to heat stress. These indicators can differentiate between mutant lines and may be used more broadly as a pre-screen for heat tolerance before field evaluation.

\section{Materials and methods}

Seed of rice (Oryza sativa L.) cultivars J-104 and A-82 were treated with proton beam 20 Gy in DUBNA (González et al., 2009), in a reactor type IBR-2 of $1.5 \mathrm{Mev}$ and a dose power of $0.36 \mathrm{~Gy} / \mathrm{min}$. The M1 seed matured embryos, and Amistad- 82 (control) seeds matured embryos were in vitro cultured $(2,4 \mathrm{D}$ (2mg.L-1) and BAP (2mg.L-1) to obtain callus and applied for regeneration in medium (Kin (4mg.L-1) and AIA (2mg.L-1). Selected in vitro derived mutant plants multiplied in green house condition as indicated in Figure 1. Seeds of best mutants were selected individually harvested for each generation, the best mutant lines were selected in under drought and heat stress conditions. This study evaluated 6 advanced lines (LP-7, LP-8, LP-9, LP-10, LP-12, LP-16) derived cv. Amistad-82 and together with five advanced M6 mutant lines: 8551, 8552, 8553, 85548555 obtained from the cv. J-104 and the local rice cultivar Amistad82 (A-82) was used as a control (standard), LP-16 is also known as a susceptible line. Evaluation of agronomical performance of advanced mutant lines under high temperature condition in the field.

The advanced mutant lines and the varieties were grown in the field under high temperature (Fig. 1) using a randomized block design with three replications. Irrigation was provided with a drip water system. At harvest, plant height, number of panicles per $\mathrm{m}^{2}$, full grains per panicle, unfilled grains per panicle, 1,000 grain weight and yield per $\mathrm{m}^{2}$ were evaluated.

\section{Evaluation of physiological and biochemical parameters of mutant lines under high temperature}

Selected lines with the best performances in the field (LP-12, $8552,8553)$ as well as the genotype with the worse performance (LP-16) and the control cv. Amistad-82 were tested under laboratory conditions for heat stress associated physiological and biochemical indicators to validate/support results and to identify heat stress tolerant genotypes.

\section{Cell membrane conductivity}

The 30-day-old leaf samples of rice genotypes were placed in vials with distilled water. The samples were placed in a temperature block at $40^{\circ} \mathrm{C}$ for 90 minutes, and controls at $25^{\circ} \mathrm{C}$, with three replications per treatment. Electric conductivity solution of each vial was determined. Complete death of leaf samples was carried out by autoclaving and then tested for electric conductivity, as this factor is needed to determine cell membrane thermo-stability (CMT) according to following formula:

Table 1. Results of yield and yield related characters in some mutant lines and varieties evaluated under high temperature in the field conditions.

\begin{tabular}{|l|l|l|l|l|l|}
\hline Genotypes & Panicle $/ \mathrm{m}^{2}$ & Full grain/panicle & Unfilled grain/panicle & 1,000 grain weight & Yield (t/ha) \\
\hline 8551 & $250 \mathrm{c}$ & $83 \mathrm{c}$ & $22 \mathrm{~cd}$ & $29.7 \mathrm{a}$ & $3.6 \mathrm{~b}$ \\
\hline 8552 & $289 \mathrm{a}$ & $95 \mathrm{a}$ & $19 \mathrm{~d}$ & $28.9 \mathrm{~b}$ & $4.2 \mathrm{a}$ \\
\hline 8553 & $297 \mathrm{a}$ & $97 \mathrm{a}$ & $19 \mathrm{~d}$ & $27.7 \mathrm{c}$ & $4.1 \mathrm{a}$ \\
\hline 8554 & $255 \mathrm{bc}$ & $89 \mathrm{~b}$ & $22 \mathrm{~cd}$ & $28.5 \mathrm{~b}$ & $3.4 \mathrm{~b}$ \\
\hline 8555 & $257 \mathrm{bc}$ & $87 \mathrm{~b}$ & $21 \mathrm{~d}$ & $27.5 \mathrm{c}$ & $3.2 \mathrm{bc}$ \\
\hline LP-7 & $264 \mathrm{~b}$ & $88 \mathrm{~b}$ & $23 \mathrm{~cd}$ & $26.4 \mathrm{~d}$ & $3.5 \mathrm{~b}$ \\
\hline LP-8 & $266 \mathrm{~b}$ & $92 \mathrm{ab}$ & $21 \mathrm{~d}$ & $27.8 \mathrm{c}$ & $3.6 \mathrm{~b}$ \\
\hline LP-9 & $267 \mathrm{~b}$ & $88 \mathrm{~b}$ & $27 \mathrm{c}$ & $27.0 \mathrm{~d}$ & $3.5 \mathrm{~b}$ \\
\hline LP-10 & $257 \mathrm{c}$ & $80 \mathrm{c}$ & $24 \mathrm{~cd}$ & $28.0 \mathrm{c}$ & $3.1 \mathrm{c}$ \\
\hline LP-12 & $290 \mathrm{a}$ & $93 \mathrm{ab}$ & $21 \mathrm{~d}$ & $27.5 \mathrm{c}$ & $4.2 \mathrm{a}$ \\
\hline LP-16 & $56.7 \mathrm{e}$ & $15 \mathrm{~d}$ & $67 \mathrm{a}$ & $25.5 \mathrm{~d}$ & $1.0 \mathrm{~d}$ \\
\hline Amistad-82 & $220 \mathrm{~d}$ & $78 \mathrm{c}$ & $36 \mathrm{~b}$ & $27.4 \mathrm{c}$ & $3.0 \mathrm{c}$ \\
\hline ES $\mathrm{x}$ & $10.21 *$ & $4.91 *$ & $4.45^{*}$ & $0.42^{*}$ & $0.31^{*}$ \\
\hline
\end{tabular}

*Means followed by a common letter(s) aren't significantly differed at 0.05 level by Tukey test. 


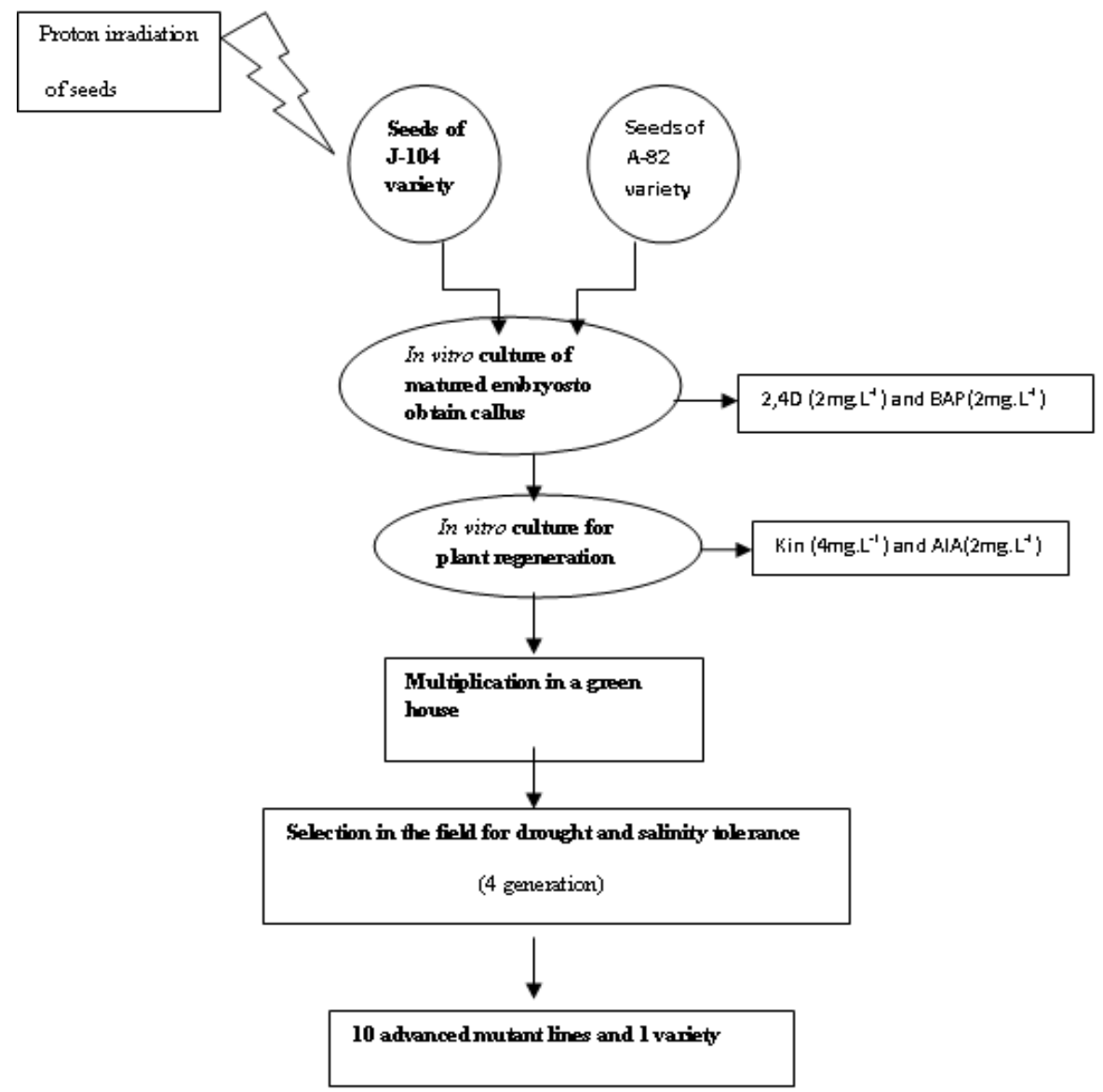

Fig 1. Applied procedure to obtain advanced lines.

Table 2. Comparison of percentage value of pollen viability of four flower from each genotype. Stress treatment ( $40^{\circ} \mathrm{C}$ for 1 hours) in growth chamber and the control $\left(25^{\circ} \mathrm{C}\right.$ for 3 hours) from independent sample test ( $\mathrm{T}$ Students) and the cell membrane thermostability in rice varieties. Stress treatment $\left(40^{\circ} \mathrm{C}\right.$ for 90 minutes) and control $\left(25^{\circ} \mathrm{C}\right)$ from Multiple Comparisons analysis (LSD).

\begin{tabular}{|l|c|c|c|c|}
\hline & Pollen viability $(\%)$ & \multicolumn{3}{c|}{ Cell membrane thermostability } \\
\hline 8553 & Control & Stress & $1.269(0.264)$ & $85.6 \mathrm{a}$ \\
\hline 8552 & 90.3 & 79.7 & $0.548(0.603)$ & $81.2 \mathrm{~b}$ \\
\hline LP-12 & 91.4 & 88.3 & $4.9180(0.08)$ & $75.4 \mathrm{c}$ \\
\hline Amistad 82 & 89.5 & 78.6 & $14.766(0.00)$ & $65.7 \mathrm{~d}$ \\
\hline LP-16 & 91.3 & 58.9 & $36.014(0.00)$ & $45.6 \mathrm{e}$ \\
\hline Std. Error & 82.3 & 36.2 & & 1.5556 \\
\hline
\end{tabular}

*The mean difference is significant at the 0.05 level.

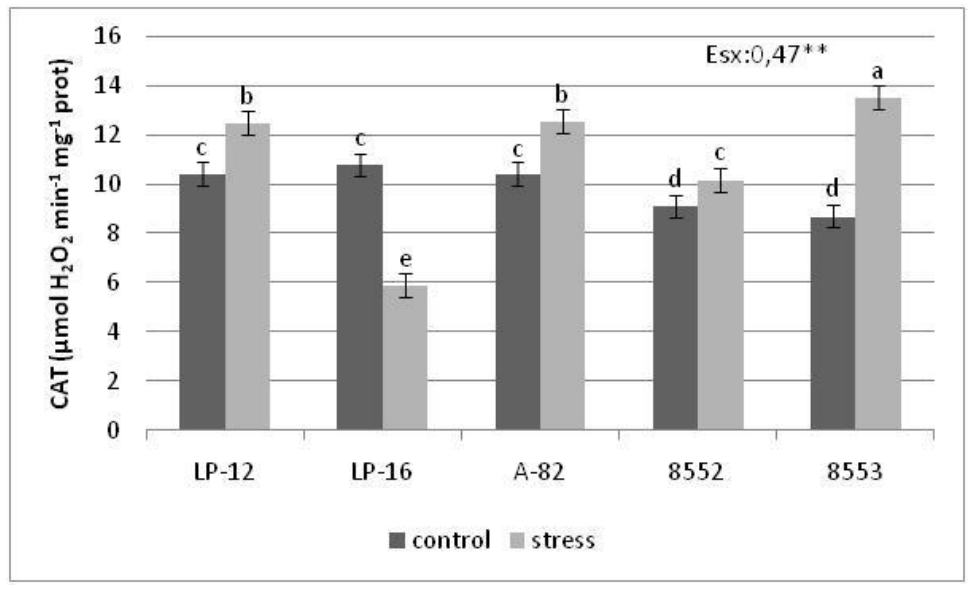

Fig 2. Specific activity of catalase (CAT) in leaves of rice mutants under stress temperature of $40^{\circ} \mathrm{C}$ for 3 hours (stress) and $25^{\circ} \mathrm{C}$ (control). 


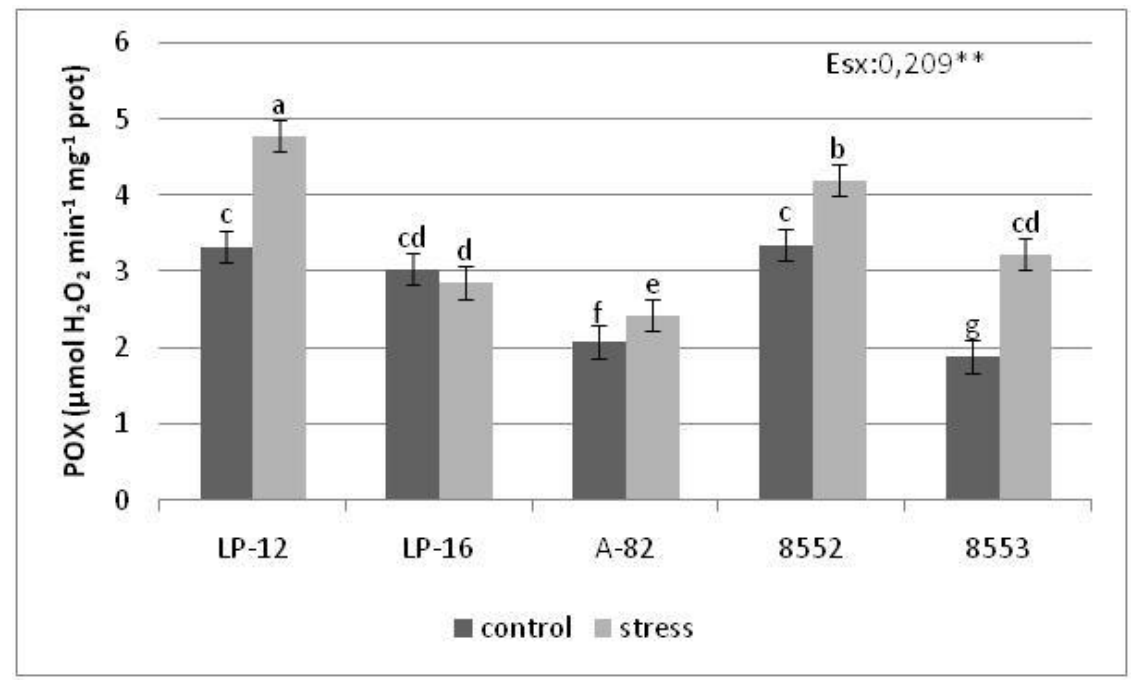

Fig 3. Peroxidase (POX) activity in leaves of rice mutants under stress temperature of $40^{\circ} \mathrm{C}$ for 3 hours (stress) and $25^{\circ} \mathrm{C}$ (control).

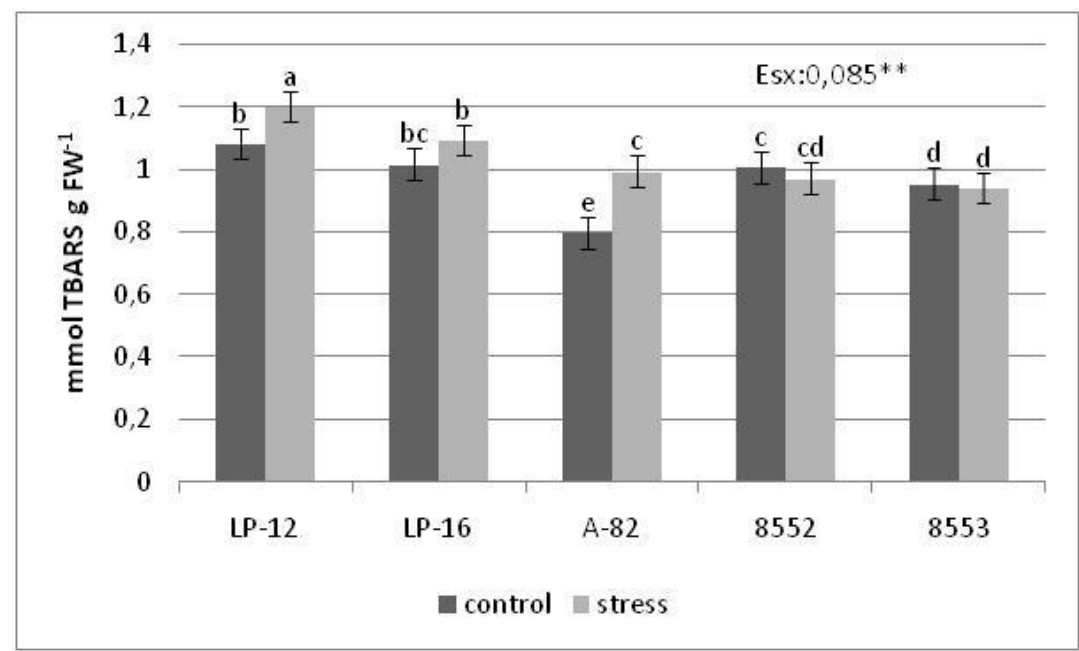

Fig 4. Malondialdehyde (MDA) in leaves of rice mutants under stress temperature of $40^{\circ} \mathrm{C}$ for 3 hours (stress) and $25^{\circ} \mathrm{C}$ (control).

\section{CMT $(\%)=(1-(\mathrm{T} 1 / \mathrm{T} 2) /(1-(\mathrm{C} 1 / \mathrm{C} 2) \mathrm{X} 100$}

T1: First conductivity measurement after heat treatment,

T2: Second conductivity measurement (after autoclaving) of heat treatment explants,

C1: First conductivity measurement of control,

C2: Second conductivity measurement (after autoclaving) of control.

\section{Pollen viability}

At the time of flowering one individual panicle per plant from five plants were treated with heat at $40^{\circ} \mathrm{C}$ for one hour in Petri dishes.

The pollen grains were extracted and stained with cotton blue in lactophenol. The numbers of coloured and non-coloured pollen grains were identified with an optical microscope and the percentage of pollen viability was determined.

\section{Biochemical evaluation}

Seeds of rice lines (LP-12, LP-16, A-82, 8552, 8553) were placed in boxes with Red ferritic soil and organic matter $(3: 11 \mathrm{v} / \mathrm{v})$. After 30 days, they were placed in boxes under high temperature condition $\left(40^{\circ} \mathrm{C}\right.$ for 3 hours) control plants were given $25^{\circ} \mathrm{C}$ in a germination cabinet. About $0.25 \mathrm{~g}$ of frozen leaves of the genotypes LP-12, LP-16, 8552 and 8553 per treatment were homogenized with $2.5 \times 10^{-3} \mathrm{~mol} \mathrm{~L}^{-1}$ of tampon phosphate of potassium, $0.1 \mathrm{~mol} \mathrm{~L}^{-1} \mathrm{pH} 7.8$; EDTA $1.0 \times 10^{-4} \mathrm{~mol} \mathrm{~L}^{-1}$; Newt x-
$1000.1 \%$ (v/v), PVPP $1.5 \%(\mathrm{p} / \mathrm{v})$ and $2.5 \mu \mathrm{g} \mathrm{L}^{-1}$ of inhibitors of proteases, aprotinin and leupeptin. The homogenate was centrifuged at $13,000 \mathrm{rpm}$ for 20 minutes, and then the supernatant was used for further analyses of the lipid peroxidation and some enzymatic activity.

\section{Peroxidase activity}

Peroxidase (POX; EC 1.11.1.1) was measured by monitoring the formation of tetra guaiacol at $470 \mathrm{~nm}\left(\varepsilon=26.6 \mathrm{mM}^{-1} \mathrm{~cm}^{-1}\right)$. The formation of "rusty" guaiacol was measured in a spectrophotometer UV/Visible (Genesys 6, Thermo Electron Corporation) by 5 second incremental absorbance at $420 \mathrm{~nm}$ at an interval of 30 seconds (Bergmeyer, 1974).

\section{Catalase activity}

Catalase (CAT; EC 1.11.1.6) was determined according to the method of Aebi (1984) in a reaction mixture containing $50 \mu \mathrm{l}$ enzyme extract in $50 \mathrm{mM}$ sodium phosphate buffer $(\mathrm{pH} 7,0)$. The decomposition of the $\mathrm{H}_{2} \mathrm{O}_{2}$ was evaluated every 10 seconds over one minute and the quantity of $\mathrm{H}_{2} \mathrm{O}_{2}$ was considered for the absorbance to $240 \mathrm{~nm}$ (extinction coefficient of the $\mathrm{H}_{2} \mathrm{O}_{2}$ to 240 $\mathrm{nm} ; 43,6 \mathrm{M}^{-1} \mathrm{~cm}^{-1}$ ) in a spectrophotometer UV/Visible (Genesys 6, Thermo Electron Corporation). 


\section{The Malondialdehydecontent}

Malondialdehyde (MDA) as an indicator of lipid peroxidation was determined according to the method described by Hodges et al. (1999). The absorbance was measured between 532 and 600 $\mathrm{nm}$ in a spectrophotometer UV/Visible (Genesys 6, Thermo Electron Corporation). Correction was applied by subtracting the absorbance at $600 \mathrm{~nm}$ using extinction coefficient of 156 $\mathrm{mM}^{-1} \mathrm{~cm}^{-1}$ (Madhava Rao and Stresty, 2000).

\section{Statistical analysis}

Data for pollen viability, cell membrane conductivity and the biochemical evaluation were expressed as means of four plants in triplicate experiments and their means and the standard deviations were calculated. Data for field evaluation for each character was carried out as a simple variance analysis and the mean differences were calculated using the Tukey test.

\section{Conclusions}

Rice is a staple food and energy source for almost half the world's population. The climatic factors such as drought and high temperature negatively affect rice production. Hence, generating mutant cultivars tolerant to these parameters areof utmost importance. In this study, advanced mutant rice lines were evaluated, and their performances were compared with stressrelated physiological and biochemical parameters in field conditions. Considering that the upper endurancelimit for rice is $35^{\circ} \mathrm{C}$, we made our analyses at $40^{\circ} \mathrm{C}$ and identified three mutant lines, 8852, 8552 and LP-12, showing tolerance to high temperatures. The selected mutantsshowed noticeably better yield and yield component performance than the susceptible lines. Physiological parameters were identified as significant indicators for heat tolerance. Regarding the biochemical parameters; while the malondialdehyde content wasidentified as not a prominent indicator, cell membrane thermostability, the peroxidase and catalase activitieswere determined as important heat stress indicators due to their varying contentsand associations with field performances in tolerant and susceptible genotype. Evaluation of the physiological and biochemical indicators together allowed us to make better field analyses for high temperature and heat stress parameters. These indicators may also be used more broadly as a pre-screen for heat tolerance before field evaluation.

\section{Acknowledgements}

We thank the support of IAEA through the Coordinated Research Project 23029 "Climate proofing of food crops: genetic improvement for adaptation to high temperatures in drought prone areas and beyond".

\section{References}

Aebi H (1984) Catalase in vitro. Meth Enzym. 105:121-126.

Acevedo M, Castrillo W, Belmonte U (2006) Origen, evolución y diversidad del arroz. Agron Tropical. 56 (2):151-170.

Bajji M, Kinet JM, Lutts S (2001) The use of the electrolyte leakage method for assessing cell membrane stability as a water stress tolerance test in durum wheat. J Plant Growth Regul. 1:1-10.

Bergmeyer HU (ed) (1974) Peroxidase (En: HU Bergmeyer, ed, Methods of Enzymatic Analysis Academic Press Inc.) 2:685690.

Blokina O, Virolainen E, Fagerstedt K (2003) Antioxidant oxidative damage and oxygen deprivation stress. Annu Rev Annal Bot. 91:179-194.

Campos PS, Quartin V, Ramalho JC, Nunes MA (2003) Electrolyte leakage and lipid degradation account for cold sensitivity in leaves of Coffea sp. Plants J Plant Physiol. 160:283-292.
CecarelliS, Grando S, Maatougy M, Michael M, Slash M, Haghparast R, Rahmanian M, Taheri A, Al-Yassin A, Benkelkacem A, Labdi M, Mimoun H, Nachit M (2010) Plantbreedingandclimatechanges. J Agr iSci. 148:627-637.

Das S, Krishnan P, Nayak M, Ramakrishnan B (2014) High temperature stress effects on pollens of rice (Oryza sativa L.) genotypes. Environ Exp Bot. 101:36-46.

Dolatabadian A, and Saleh R (2009) Impact of exogenous ascorbic acid on antioxidant activity and some physiological traits of common bean subjected to salinity stress. Not Bot Horti Agrobot Cluj Napoca. 37:165-172.

FAO/IAEA (2017) Mutant Variety Database. www.mvd.iaea.org.

González MC, Perez N, Cristo E, Rodriguez M (2008) Cuban rice mutants obtained from protons radiations. Plan Mut Rep. 2(1):9-13.

González MC, Pérez y N, Cristo y Eç, Rodríguez M (2009) Development of salinity-tolerant rice varieties using Biotechnological and Nuclear Techniques. Induced Plant Mutation in the Genomic Era. FAOUN Rep.138-140.

González MC, Pérez y N, Cristo E (2009) GINES: Primer mutante de arroz obtenido a partir de la irradiación con protones. Cultivos Tropicales. 30:3-4.

Heath RL, Packer L (1986) Photoperoxidarion in isolated chloroplasts. I. Kinetics and stoichiometry of fatty acid peroxidation. Arch Biochem Biophys. 125:189-198.

Hodges M, DeLong D, Forney JM, Prange CF (1999) Improving the thiobarbituric acid-reactive-substances assay for lipid peroxidation in plant tissues containing anthocyanin and other interfering compounds. Planta. 207:604-611.

Imlay JA (2003) Pathways of oxidative damage. Annu Rev Microbiol. 57:395-418.

Hasanuzzaman M, Nahar K, Fujita M (2013) Extreme temperatures, oxidative stress and antioxidant defense in plants. In: Vahdati K. Leslie C. (eds). Abiotic stress-plant responses and applications in agriculture. Tech Rijeka, pp. 169-205 (2013) Croatia.

Jagadish SVK, Muthurajan R, Oane R, Wheeler TR, Heuer S, Bennett J, Craufurd PQ (2010) Physiological and proteomic approaches to dissect reproductive stage heat tolerance in rice (Oryza sativa L.). J Exp Bot. 61:143-156.

Janska A, Marsik P, Zelenkova S, Ovesna J (2010) Cold stress and acclimation: What is important for metabolic adjustment. Plant Biol. 12:395-405.

Joseph B, and Jini D (2011) Development of salt stress-tolerant plants by gene manipulation of antioxidant enzymes. Asian J Agric Res. 5(1):17-27.

Kartashov AV, Raciyukina NL, Ivanov YV, Pashkovskii PP, Hevyakova N, Kuznetsov VV (2008). Role of antioxicant systems in wilci plant adaptation to salt stress. Russ J Plant Physiol. 55:463-468.

Kondamudi R, Swamy KN, Vishnuprasanth D, Rao YV, Rao PR, Sarla N, Subrahmanyam R, Voleti SR (2012) Heat stress in rice - physiological mechanisms and adaptation strategies. Crop Stress and its Management: Perspectives and Strategies, Springer Science, February. 2012.

Madhava Rao KV, and Sresty TVS (2000) Antioxidative parameters in the seedlings of pigeonpea (Cajanus Cajan $\mathrm{L}$. Millspaugh) in response to $\mathrm{Zn}$ and $\mathrm{Ni}$ stresses. Plant Sci. 157:113-28

Mittler R, Finka A, Goloubinoff P (2012) How do plants feel the heat? Trends Biochem Sci. 37:118-125.

Morejón RR, Díaz SH, Hernández JJ (2012) Comportamiento de tres variedades comerciales de arroz en áreas del complejo agroindustrial arrocero los palacios. Cultivos Tropicales. $33(1): 46-49$.

Morita S (2003) Effects of high air temperature on ripening in rice plants-analysis of ripening performance in growth chamber experiments. Jpn J Crop Sci. 69 (3):391-399.

Munns R, and Tester M (2008) Mechanisms of salinity tolerance. Ann Rev Plant Biol. 59:651-681. 
Nakano Y, and Asada K (1981) Hydrogen peroxide is scavenged by ascorbate-specific peroxidase in spinach chloroplasts. Plant Cell Physiology. 22:867-880.

Oberley LW, and Spitz DR (ed) (1985) Assay of superoxide dismutase using nitroblue tetrazolium. In: Greenwald RA, handbook of methods for oxygen radical research. Boca Raton, FL: CRC Press pp. 217-227.

Shao H (2008) Higher plant antioxidants and redox signalling under environmental stresses. C R Biol. 331(3):433-441.

Sullivan CY, Norcio NV, Eastin JD (ed) (1977) Plant response to high temperature. "genetic diversity in plants", eds by A. Muhammed, R. Aksel, and R. C. Von Borstel, Plenum Publishing Corp. 301-317.

Tembo L, and Munyinda K (2015) Clustering common bean mutants based on heterotic groupings. AJOL. 3(1): 1-7.

Wang W, Vinocur B, Altman A (2003) Plant responses to drought, salinity and extreme temperatures: towards genetic engineering for stress tolerance. Planta. 218(1): 1-14.

Watanabe T, and Kume T (2009) A general adaptation strategy for climate change impacts on paddy cultivation: special reference to the Japanese context. Paddy Water Environ. 9:313-320.
Yang J, and Zhang J (2006) Grain filling of cereals under soil drying. New Phytol. 169:223-236.

Yin X, Kroff MJ, Goudriann J (1996) Differential effects of day and night temperature on development to flowering in rice. Annal Bot. 6:203-213.

Yoshida Y (2006) Fundamentals of rice crops science. International Rice Research Institute, Los Banos, Philippines, August 2006.

Zakaria S, Matsuda T, Tajima S, Nitta Y (2004) Effect of high temperature at ripening stage on the reserve accumulation in seed in some rice cultivars. Plant Prod Sci. 5(2):160-168.

Ziska LH, and Manalo PA (1996) Increasing night temperature can reduce seed set and potential yield of tropical rice. Aust Plant Physiol. 23(6):791-794. 